\title{
Syringomyelia intermittens: highlighting the complex pathophysiology of syringomyelia. Illustrative case
}

\author{
Jorn Van Der Veken, MD, ${ }^{1}$ Marguerite Harding, MBChB, FRACS, ${ }^{1}$ Saba Hatami, MBBS (Hons), FRANZCR, ${ }^{2,3}$ \\ Marc Agzarian, BMBS(Hons), FRANZCR, ${ }^{2,3}$ and Nick Vrodos, MBBS, FRACS ${ }^{1}$ \\ ${ }^{1}$ Neurosurgery Department and ${ }^{2}$ South Australia Medical Imaging, Flinders Medical Centre, Bedford Park, South Australia, Australia; and ${ }^{3}$ College of Medicine \& Public Health,
Flinders University, Bedford Park, South Australia, Australia
}

\begin{abstract}
BACKGROUND Chiari Type I malformation (CM1) is a disorder recognized by caudal displacement of the cerebellar tonsils through the foramen magnum and into the cervical canal. Syringomyelia is frequently found in patients with CM1, but the pathophysiology of syringomyelia remains an enigma. As a general consensus, symptomatic patients should be treated and asymptomatic patients without a syrinx should not be treated. Mildly symptomatic patients or asymptomatic patients with a syrinx, on the other hand, pose a more challenging dilemma, as the natural evolution is uncertain. For many surgeons, the presence of a syrinx is an indication to offer surgery even if the patient is asymptomatic or mildly symptomatic.

OBSERVATIONS The authors describe an illustrative case of a 31-year-old female with an incidental finding of a CM1 malformation and cervical syrinx in 2013. Conservative management was advocated as the patient was asymptomatic. Monitoring of the syrinx over a course of 8 years showed resolution, followed by reappearance and finally a complete resolution in 2021 . A review of the literature and the possible pathophysiology is discussed.
\end{abstract}

LESSONS The unusual course of this patient highlights the importance of guiding treatment by clinical symptoms, not radiological findings. Furthermore it reflects the complexity of the pathophysiology and the uncertain natural history of syringomyelia.

https://thejns.org/doi/abs/10.3171/CASE21341

KEYWORDS intermittent; syringomyelia; Chiari 1

Chiari Type I malformation (CM1) is a disorder characterized by caudal displacement of 1 or both of the cerebellar tonsils through the foramen magnum and into the cervical canal. It was originally described by Arnold Chiari in 1891 as an "elongation of the tonsils and the medial part of the inferior lobes of the cerebellum into cone-shaped projections which accompany the medulla oblongata into the spinal canal." Cerebellar tonsillar ectopia is generally considered pathological when greater than $5 \mathrm{~mm}$ below the foramen magnum or McRae line. The 5-mm limit originates from older studies comparing the descent of cerebellar tonsils in healthy volunteers with those in patients who had symptomatic $\mathrm{CM} 1 .^{2,3}$ The estimated prevalence of CM1 is probably between $0.24-0.9 \%$ of the population, and the majority of these patients are asymptomatic. ${ }^{2-5}$
Despite CM1 being studied for 130 years, many questions regarding the pathophysiology and expected evolution still remain. ${ }^{1}$ Symptomatic patients should be treated and asymptomatic patients without a syrinx should not be treated. As the natural evolution of mildly symptomatic patients or asymptomatic patients with a syrinx is uncertain, they pose a greater treatment dilemma, For many surgeons the presence of a syrinx is an indication to offer surgery even if the patient is asymptomatic or mildly symptomatic. ${ }^{6}$ However, as this case illustrates, resolution or recurrence of a syrinx might occur spontaneously.

\section{Illustrative Case}

Eight years ago, a 24-year-old female was involved in a car accident, with brief loss of consciousness. As part of the radiological trauma

ABBREVIATIONS CM1 = Chiari Type I malformation; CSF = cerebrospinal fluid; CT = computed tomography; MRI = magnetic resonance imaging; PFD = posterior fossa decompression; PFDD = posterior fossa decompression with duraplasty; SAS = subarachnoid space.

INCLUDE WHEN CITING Published September 13, 2021; DOI: 10.3171/CASE21341.

SUBMITTED June 3, 2021. ACCEPTED July 12, 2021.

(C) 2021 The authors, CC BY-NC-ND 4.0 (http://creativecommons.org/licenses/by-nc-nd/4.0/). 


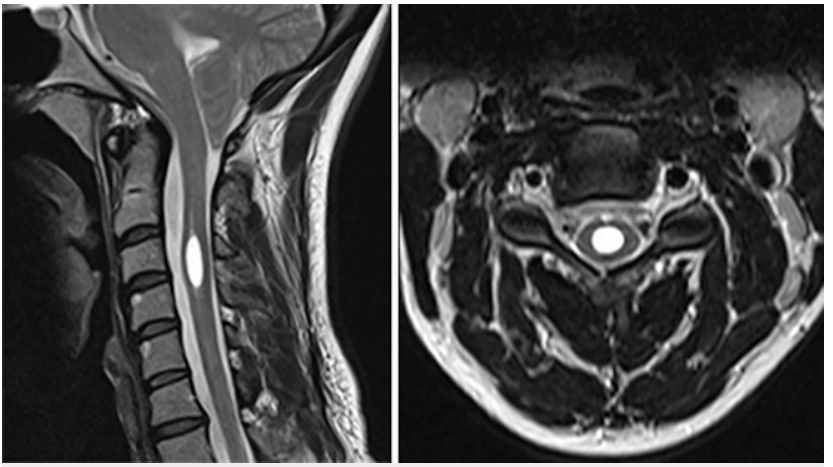

FIG. 1. Left: Sagittal T2-weighted spin-echo MRI February 2013.

Right: Axial T2-weighted spin echo MRI in February 2013.

protocol, computed tomography (CT) of the brain and full spine was performed. No intracranial or spinal traumatic lesions were seen. However, a CM1 was seen with a suspicion of a syrinx at C3. Further investigations with magnetic resonance imaging (MRI) of the brain and full spine confirmed a CM1 with a tonsillar descent of $12 \mathrm{~mm}$ reaching down to the posterior arch of $\mathrm{C} 1$ and an associated syrinx at $\mathrm{C} 3$ measuring $6 \times 18$ $\mathrm{mm}$ (Fig. $1 A$ and $B$ ). The MRI of the full spine did not show any other abnormality.

As the patient was completely asymptomatic, conservative management was recommended with follow-up MRI in 6 months. This follow-up MRI showed an almost complete resolution of the syrinx as well as a mild improvement of the tonsillar descent at the foramen magnum (Fig. 2).

Two years later, another MRI was performed, with the expectation of seeing a complete resolution of the syrinx; however, this MRI showed a recurrence of the syrinx with the cerebellar tonsils sitting again at the level of the posterior arch of $\mathrm{C} 1$ (Fig. 3). At the time, the patient was still asymptomatic, and the decision was made to repeat imaging if the patient developed symptoms.

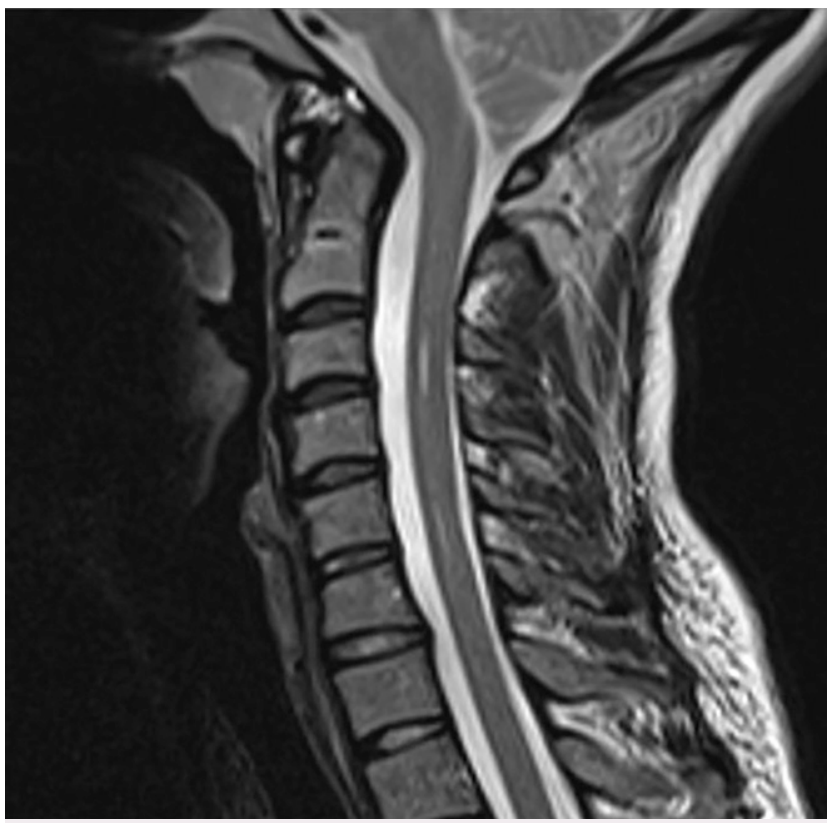

FIG. 2. Sagittal T2-weighted spin-echo MRI in July 2013.

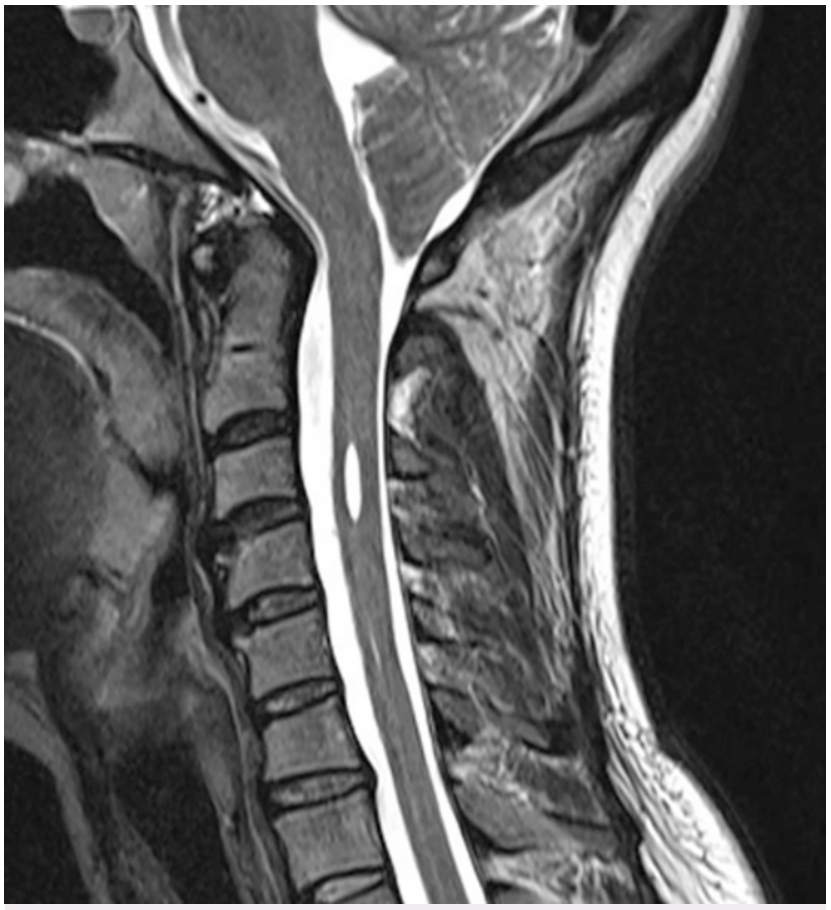

FIG. 3. Sagittal T2-weighted spin-echo MRI in June 2016.

Recently, the patient was referred back to the Neurosurgical Department by her primary care provider with severe persistent neck pain and occipital headaches following an awkward maneuver during housework. An MRI of the brain and full spine was performed, demonstrating complete resolution of the syrinx and significant improvement of the tonsillar descent (Fig. 4). The patient was seen in the outpatient clinic and mentioned a resolution of her symptoms after a short course of nonsteroidal antiinflammatory drugs. The anamnesis was most compatible with a muscular or facetogenic cause for these transient symptoms.

\section{Discussion \\ Observations}

The exact pathophysiology of syringomyelia due to CM1 remains frustratingly uncertain. Five theories have been proposed. The first theory was proposed by Gardner and Angel in 1958; the "waterhammer" theory states that "partial obstruction of the outflow of cerebrospinal fluid (CSF) from the fourth ventricle directs the systolic pulsations of CSF from the fourth ventricle through a patent central canal." ${ }^{77}$ The second theory was the "cranial-spinal pressure dissociation" theory proposed by Williams in 1969, stating that a block in caudal, but not upward, CSF flow causes an increase of intracranial pressure over spinal intrathecal pressure and, as such, forces CSF from the fourth ventricle down into the central canal, producing "communicating" syringomyelia. ${ }^{8}$ Therefore, both postulate communication between the fourth ventricle and the syrinx via the obex and the central canal; however, this communication is seldom seen on MRI or autopsy. ${ }^{9}$

A third theory published in 1972 by Ball and Dayan suggested that the tonsils obstruct the rapid rostral movement of CSF from the spinal subarachnoid space (SAS) to the cranial SAS during transiently increased thoracic venous pressure, causing sporadic increased 


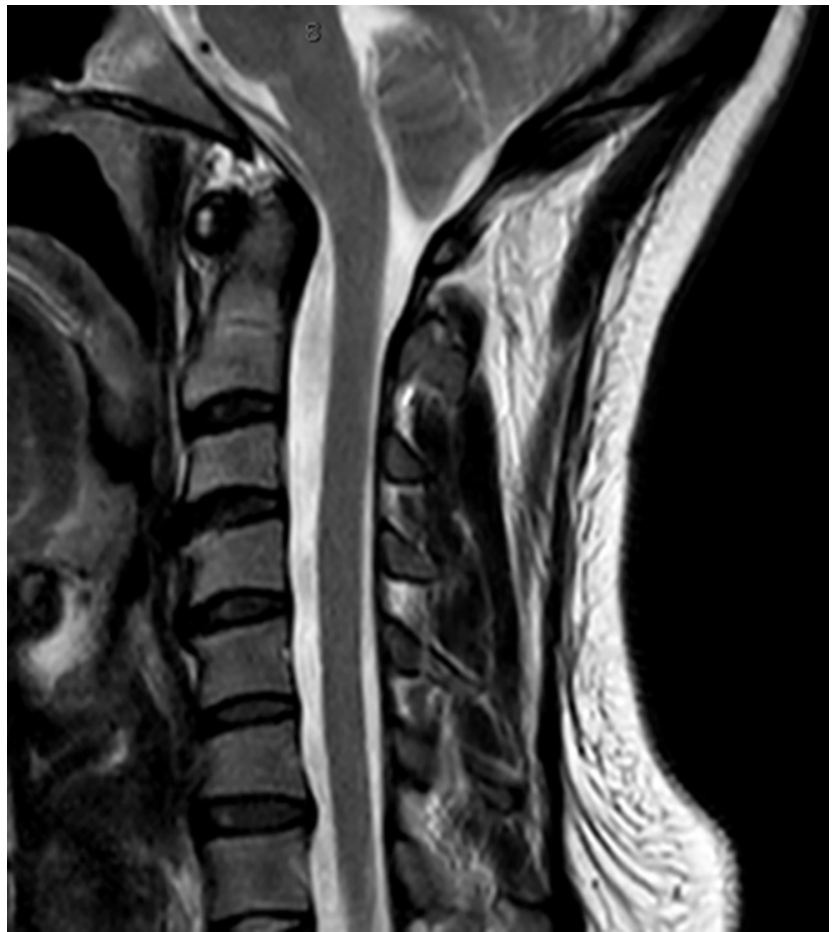

FIG. 4. Sagittal T2-weighted spin-echo MRI in February 2021, showing disappearance of the syrinx and clear CSF high T2 signal at the foramen magnum and rounder cerebellar tonsils.

spinal CSF pressure; this forces the CSF along extracellular paths through the spinal cord surface to initiate syringomyelia. ${ }^{10}$ The work by Oldfield et al. showed compression of the upper part of the syrinx during systole; the theory was refuted. ${ }^{11}$ However, the role of the dilated Virchow-Robin spaces to initiate syringomyelia has been confirmed. $^{12}$

Based on this theory, a fourth hypothesis was introduced by Oldfield and colleagues, "the piston theory." This theory suggests that "syrinx formation is caused by the cerebellar tonsils acting as a piston to produce large pressure waves in the spinal subarachnoid space, and this action forces fluid through the surface of the spinal cord or the perivascular spaces into the central canal. Once formed, such syringes are believed to enlarge due to external compression of the cord." 11

Stoodley et al. suggested a fifth theory stating that CSF normally flows along the perivascular spaces from the spinal subarachnoid space, but perturbations of this flow caused by Chiari malformations or other conditions are responsible for the initiation of a cyst formation and enlargement (due to increased inflow or reduced outflow). ${ }^{12}$

Despite more than half of century of research, it is still unclear why some patients with CM1 develop a syrinx and others do not. Leung et al. showed no difference in cerebellar tonsillar motion between patients with and without syrinx. ${ }^{13}$ And although most patients with a CM1 have a "crowded" posterior fossa, a small number of patients have a spacious posterior fossa but nonetheless demonstrate herniation of their tonsils. ${ }^{14}$

Whatever the exact pathophysiology might be for the development of syringomyelia in patients with $\mathrm{CM} 1$, we know that surgically restoring CSF flow at the foramen magnum or bypassing the obstruction with a shunt alleviates the symptoms and the syrinx. $3,12,15,16$
Spontaneous resolution has been reported frequently in children due to growth of the skull and subsequent restoration of CSF flow. ${ }^{17}$ In adults, on the other hand, the treatment for symptomatic syringomyelia is generally surgery. ${ }^{14}$

A wide range of techniques have been described from simple bony decompression to more extensive surgery with coagulation or aspiration of tonsils and duraplasty. In some cases, the extra room required at the foramen magnum for successful surgery may be only a fraction of a millimeter. ${ }^{12}$

A recent systematic review and metaanalysis compared the 2 most commonly used techniques: posterior fossa decompression with duraplasty (PFDD) and without duraplasty (PFD). ${ }^{18}$ They evaluated 3618 pediatric and adult patients. The reported results with both techniques were excellent: a clinical improvement of $86.8 \%$ in the PFDD group (77.6\% improvement in adults, $93.3 \%$ in children) versus a $69.8 \%$ in the PFD cohort $62.9 \%$ improvement in adults, $74.8 \%$ in children). ${ }^{18}$ As simple bony decompression is not sufficient in about $10 \%$ of the adult patients, it again reflects the heterogeneity of the patient population. ${ }^{13}$ When a duraplasty is performed, either an autologous graft (pericranium) or a nonautologous graft (synthetic, bovine pericardium, collagen-based, allograft) can be used. A recent metaanalysis shows superiority of autologous grafts versus nonautologous in terms of complications. ${ }^{19}$

Despite an estimated prevalence of $\mathrm{CM} 1$ between $0.24-0.9 \%$, there is a paucity of data reporting on the natural history of adult CM1. Langridge et al. performed a systematic review on the natural history of patients with CM1 and could only include 1 article describing the natural history in asymptomatic patients and 2 articles following up symptomatic patients who were conservatively managed. ${ }^{6}$ Five asymptomatic patients were followed for a mean of 2 years and remained asymptomatic. $^{6}$

Twenty cases of spontaneous resolution of a syrinx in patients with CM1 have been previously described. ${ }^{20-36}$ In about half of them, an association with improvement of the tonsillar herniation is described, similar to our case. Recurrence after spontaneous resolution has been described in only 1 other case. ${ }^{26}$ This is the first report of a spontaneous resolution after a recurrence.

An improvement of CSF flow at the foramen magnum due to spontaneous rupture of the arachnoid adhesions, typically encountered at the foramen magnum, has been suggested by 4 different authors. ${ }^{25,27,33,35}$ Others have reported spontaneous improvement of CM1 due to brain atrophy in ageing patients. ${ }^{37,38}$

Lifestyle changes, such as avoiding straining and breath holding and ceasing hard physical labor, have been described, leading to a resolution of syringomyelia due to reduced venous pressure. ${ }^{6,11} \mathrm{~A}$ prospective trial was conducted by the group of Oldfield, which included 18 patients with $\mathrm{CM} 1$ and showed a significant improvement of CSF flow at the foramen magnum by simply flexing the head. ${ }^{39}$ Apart from starting meditation, our patient did not have any significant lifestyle changes. Whether meditation caused a change in posture or reduced intrathoracic pressure is questionable, although it could explain the intermittent character.

Raised intracranial pressure due to a space-occupying lesion (chronic subdural hematomas, cavernoma), hydrocephalus, head injuries, and venoocclusive disease have been described as a cause for tonsillar herniation. None of these was present in our patient. $^{40-44}$ A CSF leak as a cause of reduced intracranial pressure and subsequent resolution of $\mathrm{CMI}$ has also been reported. ${ }^{28}$ 
Other pathophysiological mechanisms for spontaneous resolution have been proposed, when a change in tonsillar descent is absent or less clear. In 1991, Jack et al. published a hypothesis of spontaneous drainage of a syrinx into the spinal subarachnoid space, due to pressure necrosis of the spinal cord, ${ }^{20}$ a hypothesis supported by Santoro et al. and Multani et al., who had MRI findings suggestive of a CSF channel between the syrinx and the subarachnoid space. ${ }^{21,36}$ The efficacy of syringosubarachnoid shunts in the treatment of syringomyelia supports this. ${ }^{14}$ However, this would be in conflict with the theory of Oldfield and Heiss that the mechanism of a syrinx origin and resolution arises outside, not inside, the spinal cord. ${ }^{45}$

It is possible that there are 2 distinct pathophysiological mechanisms leading to spontaneous resolution of a syringomyelia; however, as can be seen in our case, a subtle decrease in tonsillar herniation might easily be missed, and a subtle improvement in flow at the craniocervical junction might be sufficient to restore CSF flow and resolve the syrinx. Both mechanisms (spontaneous improvement of CSF flow at the foramen magnum and spontaneous drainage of the syrinx into the spinal subarachnoid space) support the hypothesis of Stoodley et al. that cyst volume and pressure are a function of the balance between inflow and outflow of CSF via the perivascular spaces. ${ }^{11}$

\section{Lessons}

The unusual course of this patient highlights the importance of guiding treatment by clinical symptoms, not radiological findings. Furthermore, it reflects the complexity of the pathophysiology and the uncertain natural history of syringomyelia.

\section{References}

1. Chiari H. Ueber Veränderungen des Kleinhirns infolge von Hydrocephalie des 368 Grosshirns. Dtsch Med Wochenschr. 1891;17(42):1172-1175.

2. Meadows J, Kraut M, Guarnieri M, Haroun RI, Carson BS. Asymptomatic Chiari Type I malformations identified on magnetic resonance imaging. J Neurosurg. 2000;92(6):920-926.

3. Milhorat TH, Chou MW, Trinidad EM, et al. Chiari I malformation redefined: clinical and radiographic findings for 364 symptomatic patients. Neurosurgery. 1999;44(5):1005-1017.

4. Vernooij MW, Ikram MA, Tanghe HL, et al. Incidental findings on brain MRI in the general population. N Engl J Med. 2007;357(18): $1821-1828$.

5. Kahn EN, Muraszko KM, Maher CO. Prevalence of Chiari I malformation and syringomyelia. Neurosurg Clin N Am. 2015;26(4): 501-507.

6. Langridge $B$, Phillips E, Choi D. Chiari Malformation Type 1: a systematic review of natural history and conservative management. World Neurosurg. 2017;104:213-219.

7. Gardner WJ, Angel J. The mechanism of syringomyelia and its surgical correction. Clin Neurosurg. 1958;6:131-140.

8. Williams $B$. The distending force in the production of communicating syringomyelia. Lancet. 1969;2(7622):696.

9. Haughton V, Mardal KA. Spinal fluid biomechanics and imaging: an update for neuroradiologists. AJNR Am J Neuroradiol. 2014;35(10): 1864-1869.

10. Ball MJ, Dayan AD. Pathogenesis of syringomyelia. Lancet. 1972;300(7781):799-801.

11. Oldfield EH, Muraszko K, Shawker TH, Patronas NJ. Pathophysiology of syringomyelia associated with Chiari I malformation of the cerebellar tonsils. Implications for diagnosis and treatment. J Neurosurg. 1994;80(1):3-15.
12. Stoodley MA, Jones NR, Yang L, Brown CJ. Mechanisms underlying the formation and enlargement of noncommunicating syringomyelia: experimental studies. Neurosurg Focus. 2000;8(3):E2.

13. Leung V, Magnussen JS, Stoodley MA, Bilston LE. Cerebellar and hindbrain motion in Chiari malformation with and without syringomyelia. J Neurosurg Spine. 2016;24(4):546-555.

14. Oldfield EH. Pathogenesis of Chiari I - pathophysiology of syringomyelia: implications for therapy: a summary of 3 decades of clinical research. Neurosurgery. 2017;64(CN_suppl_1):66-77.

15. Soleman J, Roth J, Bartoli A, Rosenthal D, Korn A, Constantini S. Syringo-subarachnoid shunt for the treatment of persistent syringomyelia following decompression for Chiari Type I malformation: surgical results. World Neurosurg. 2017;108:836-843.

16. Milhorat TH, Johnson WD, Miller JI. Syrinx shunt to posterior fossa cisterns (syringocisternostomy) for bypassing obstructions of upper cervical theca. J Neurosurg. 1992;77(6):871-874.

17. Strahle J, Muraszko KM, Kapurch J, Bapuraj JR, Garton HJ, Maher CO. Natural history of Chiari malformation Type I following decision for conservative treatment. J Neurosurg Pediatr. 2011;8(2):214-221.

18. Tam SKP, Brodbelt A, Bolognese PA, Foroughi M. Posterior fossa decompression with duraplasty in Chiari malformation type 1: a systematic review and meta-analysis. Acta Neurochir (Wien). 2021;163(1):229-238.

19. Yahanda AT, Simon LE, Limbrick DD. Outcomes for various dural graft materials after posterior fossa decompression with duraplasty for Chiari malformation type I: a systematic review and meta-analysis. J Neurosurg. 2021. DOI: https://doi.org/10.3171/2020.9. JNS202641.

20. Jack CR Jr, Kokmen E, Onofrio BM. Spontaneous decompression of syringomyelia: magnetic resonance imaging findings. Case report. J Neurosurg. 1991;74(2):283-286.

21. Santoro A, Delfini R, Innocenzi G, Di Biasi C, Transimeni G, Gualdi G. Spontaneous drainage of syringomyelia. Report of two cases. J Neurosurg. 1993;79(1):132-134.

22. Pierallini $A$, Ferone $E$, Colonnese $C$. [Magnetic resonance imaging of a case of spontaneous resolution of syringomyelia associated with type I Chiari malformation] [Article in Italian]. Radiol Med (Torino). 1997;93(5):621-622.

23. Fukutake T, Hattori T. Reversible hydromyelia in a synchronised swimmer with recurrent thoracic girdle pains. I Neurol Neurosurg Psychiatry. 1998;65(4):606.

24. Sudo K, Tashiro K, Miyasaka K. Features of spontaneous improvement in syringomyelia with low-situated cerebellar tonsils. Acta Neurol Belg. 1998;98(4):342-346.

25. Klekamp J, laconetta G, Samii M. Spontaneous resolution of Chiari I malformation and syringomyelia: case report and review of the literature. Neurosurgery. 2001;48(3):664-667.

26. Itoyama Y, Kitamura I, Ushio Y. [Spontaneous resolution of cervical syringomyelia. A case report] [Article in Japanese]. No Shinkei Geka. 2001;29(4):321-324.

27. Kyoshima K, Bogdanov El. Spontaneous resolution of syringomyelia: report of two cases and review of the literature. Neurosurgery. 2003;53(3):762-769.

28. Coppa ND, Kim HJ, McGrail KM. Spontaneous resolution of syringomyelia and Chiari malformation Type I in a patient with cerebrospinal fluid otorrhea. Case report. J Neurosurg. 2006;105(5):769-771.

29. Sung WS, Chen YY, Dubey A, Hunn A. Spontaneous regression of syringomyelia-review of the current aetiological theories and implications for surgery. J Clin Neurosci. 2008;15(10):1185-1188.

30. Deniz FE, Oksüz E. Spontaneous syringomyelia resolution at an adult Chiari type 1 malformation. Turk Neurosurg. 2009;19(1): 96-98.

31. Vaquero J, Ferreira E, Parajón A. Spontaneous resolution of syrinx: report of two cases in adults with Chiari malformation. Neurol Sci. 2012;33(2):339-341. 
32. Tortora F, Napoli M, Caranci F, et al. Spontaneous regression of syringomyelia in a young patient with Chiari type I malformation. Neuroradiol J. 2012;25(5):593-597.

33. Muthukumar N, Christopher J. Spontaneous resolution of Chiari I malformation and associated syringomyelia following parturition. Acta Neurochir (Wien). 2013;155(5):817-818.

34. Jain PK, Sreeharsha SV, Dugani S. Spontaneous resolution of syringomyelia in Chiari I malformation: a review of literature. Neurol India. 2017;65(5):1187-1189.

35. Yuan $C$, Yao Q, Zhang C, Jian F. Spontaneous resolution of syringomyelia with a 16-year serial magnetic resonance imaging followup: a case report and literature review. World Neurosurg. 2019;130:432-438.

36. Multani KM, Rajesh BJ, Kumar K, Kumar A. Anterior spinal cord fissuring: a predictor of spontaneous resolution of syrinx? Neurospine. 2021;18(1):240-244.

37. Mikulis DJ, Diaz O, Egglin TK, Sanchez R. Variance of the position of the cerebellar tonsils with age: preliminary report. Radiology. 1992;183(3):725-728.

38. Castillo M, Wilson JD. Spontaneous resolution of a Chiari I malformation: MR demonstration. AJNR Am J Neuroradiol. 1995;16(5): $1158-1160$.

39. Bond AE, Jane JA Sr, Liu KC, Oldfield EH. Changes in cerebrospinal fluid flow assessed using intraoperative MRI during posterior fossa decompression for Chiari malformation. $J$ Neurosurg. 2015;122(5):1068-1075.

40. Girard N, Lasjaunias P, Taylor W. Reversible tonsillar prolapse in vein of Galen aneurysmal malformations: report of eight cases and pathophysiological hypothesis. Childs Nerv Syst. 1994;10(3): 141-147.

41. Morioka T, Shono T, Nishio S, Yoshida K, Hasuo K, Fukui M. Acquired Chiari I malformation and syringomyelia associated with bilateral chronic subdural hematoma. Case report. J Neurosurg. 1995;83(3):556-558.
42. Olivero WC, Dinh DH. Chiari I malformation with traumatic syringomyelia and spontaneous resolution: case report and literature review. Neurosurgery. 1992;30(5):758-760.

43. Sun JC, Steinbok P, Cochrane DD. Spontaneous resolution and recurrence of a Chiari I malformation and associated syringomyelia. Case report. J Neurosurg. 2000;92(2 Suppl):207-210.

44. Miele WR, Schirmer CM, Yao KC, Heilman CB. Spontaneous resoIution of a Chiari malformation Type I and syrinx after supratentorial craniotomy for excision of a cavernous malformation. J Neurosurg. 2012;116(5):1054-1059.

45. Heiss JD, Patronas N, DeVroom HL, et al. Elucidating the pathophysiology of syringomyelia. J Neurosurg. 1999;91(4): 553-562.

\section{Disclosures}

The authors report no conflict of interest concerning the materials or methods used in this study or the findings specified in this paper.

\section{Author Contributions}

Conception and design: Van Der Veken, Hatami. Acquisition of data: Van Der Veken, Agzarian. Analysis and interpretation of data: Van Der Veken, Hatami, Agzarian. Drafting the article: Van Der Veken. Critically revising the article: Hatami, Harding, Agzarian, Vrodos. Reviewed submitted version of manuscript: Van Der Veken, Harding, Hatami, Vrodos. Approved the final version of the manuscript on behalf of all authors: Van Der Veken. Administrative/technical/material support: Van Der Veken. Study supervision: Harding, Vrodos.

\section{Correspondence}

Jorn Van Der Veken: Flinders Medical Centre, Bedford Park, South Australia, Australia. jornvanderveken@gmail.com; jorn.vanderveken@ sa.gov.au. 